DOI: 10.35784/IAPGOS.205

\title{
EVALUATION OF THE ELECTRICAL CAPACITANCE TOMOGRAPHY SYSTEM FOR MEASUREMENT USING 3D SENSOR
}

\author{
Jacek Kryszyn, Damian Wanta, Waldemar T. Smolik \\ Warsaw University of Technology, Division of Nuclear and Medical Electronics, Institute of Radioelectronics and Multimedia Technology, Warsaw, Poland
}

Abstract. Further tests of EVT4 data acquisition system for electrical capacitance tomography are presented. The modular system, which can have up to 32 channels with an individual analogue to digital converter, was designed to ensure small uncertainty of capacitance measurement at high speed of imaging. The system's performance in the context of $3 D$ imaging was experimentally verified. In particular, we show that the measurement of changes in capacitance due to a small change of an electric permittivity distribution for the most distant electrodes in a suitably designed $3 D$ sensor is possible using our system. Cross-plane measurements together with the measurements for the pairs of most distant electrodes are essential for accurate reconstruction of $3 D$ distributions. Due to sensitivity of capacitance measurements obtained in the hardware, the measurements for all electrode pairs can be used in the inverse problem - the system of equations can be extended. Although the numerical condition number of a matrix of such a system is high, image reconstruction is possible from the data obtained in our system. The results of $3 D$ image reconstruction for simple test objects are shown.

Keywords: electrical capacitance tomography, image reconstruction, capacitance measurement, inverse problems, numerical stability

\section{OCENA SYSTEMU ELEKTRYCZNEJ TOMOGRAFII POJEMNOŚCIOWEJ DO POMIARÓW Z WYKORZYSTANIEM SONDY 3D}

\begin{abstract}
Streszczenie. Przedstawiono dalsze testy systemu akwizycji danych EVT4 do elektrycznej tomografii pojemnościowej. Modułowy system, który może mieć do 32 kanałów z indywidualnym przetwornikiem analogowo-cyfrowym, został zaprojektowany w celu zapewnienia matej niepewności pomiaru pojemności przy dużej prędkości obrazowania. Wydajność systemu w kontekście obrazowania $3 D$ została zweryfikowana eksperymentalnie. W szczególności pokazujemy, że możliwy jest pomiar zmian pojemności wywoływanych niewielka zmiana rozkładu przenikalności elektrycznej dla najbardziej odległych elektrod odpowiednio zaprojektowanego czujnika $3 D$ przy pomocy naszego systemu. Pomiary międzypłaszczyznowe wraz z pomiarami par elektrod najbardziej odlegtych sa niezbędne do dokładnej rekonstrukcji rozktadów 3D. Ze względu na wrażliwość pomiarów pojemności uzyskanych $w$ opracowanym urządzeniu, pomiary dla wszystkich par elektrod moga być wykorzystane w problemie odwrotnym - układ równań może zostać rozszerzony. Chociaż współczynnik uwarunkowania numerycznego macierzy takiego układu jest wysoki, możliwa jest rekonstrukcja obrazu $z$ wykorzystaniem danych uzyskiwanych w naszym systemie. Pokazane sq wyniki rekonstrukcji obrazu 3D dla prostych obiektów testowych.
\end{abstract}

Słowa kluczowe: elektryczna tomografia pojemnościowa, rekonstrukcja obrazów, pomiar pojemności, problem odwrotny, stabilność numeryczna

\section{Introduction}

Electrical capacitance tomography (ECT) enables visualization of a spatiotemporal distribution of electric permittivity [8]. High frame rate which can be provided by the hardware makes this technique an important research tool in chemical and process engineering [4]. The application of ECT is limited by low spatial resolution resulting from poor spatial sampling i.e. small number of sensing electrodes in the tomographic sensor [35]. The number of electrodes cannot be increased due to a very low value of mutual capacitance of opposite electrodes. Particularly, in case of a three dimensional electrode layout in the tomographic sensor, the capacitance value of most distant electrodes is very low, of the order of a few femtofarads. A problem of measurement of extremely low capacitance values in a $3 \mathrm{D}$ sensor is the major barrier in the development of 3D ECT $[1,31]$.

Although feasibility of 3D ECT (or electrical capacitance volume tomography - ECVT) is an open question [34], 3D process visualization using ECT raises interest [16, 22, 23, 29, 32]. The theoretical advantage of 3D ECT lies in correct modelling of inherently 3D electric field distribution in a tomographic sensor that assures correctness of the model used in solving of the ECT inverse problem. Single plane measurements enable only coarse approximation of electric permittivity distribution in a cross section of an examined volume.

Specialized measurement methods were elaborated by several groups to overcame problems with very small capacitance measurement in ECT [5, 7, 10, 17, 33]. New ECT and EIT hardware was developed to increase the throughput of contemporary data acquisition systems $[3,9,28,30,38]$. The state of the art in measurement methods and data acquisition systems development for ECT together with performance comparison was presented in [13] and [24].

The construction of hardware for ECT has been developed in our laboratory for two decades $[2,21]$. The EVT4 data acquisition system - our latest design - is a modular system which can have up to 32 channels [13]. Theoretically, due to the number of channels and the high signal to noise ratio (SNR) it can be used for measurements with a 3D tomographic sensor. In this paper an experimental verification of performance of our tomographic system working with a 3D sensor is presented. The suitability of EVT4 data acquisition system for 3D tomography is analyzed.

\section{Methods}

\subsection{Small capacitance measurement method in EVT4 data acquisition system}

The architecture of the EVT4 hardware is based on fast programmable devices [13]. The multi-channel system is modular and can have from 4 to 32 channels (Fig. 1). An individual analogue to digital converter in each channel and multi gigabit serial transmission enable high data throughput required in dynamic imaging.

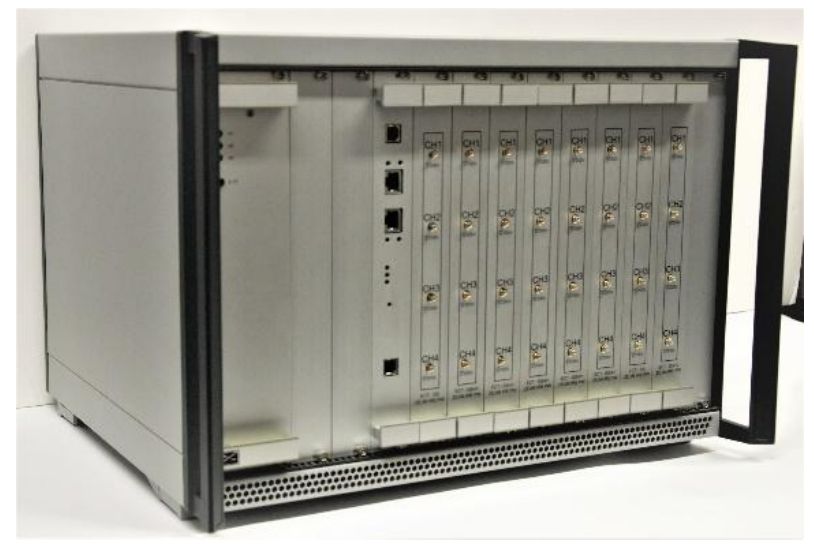

Fig. 1. EVT4 data acquisition system for ECT 


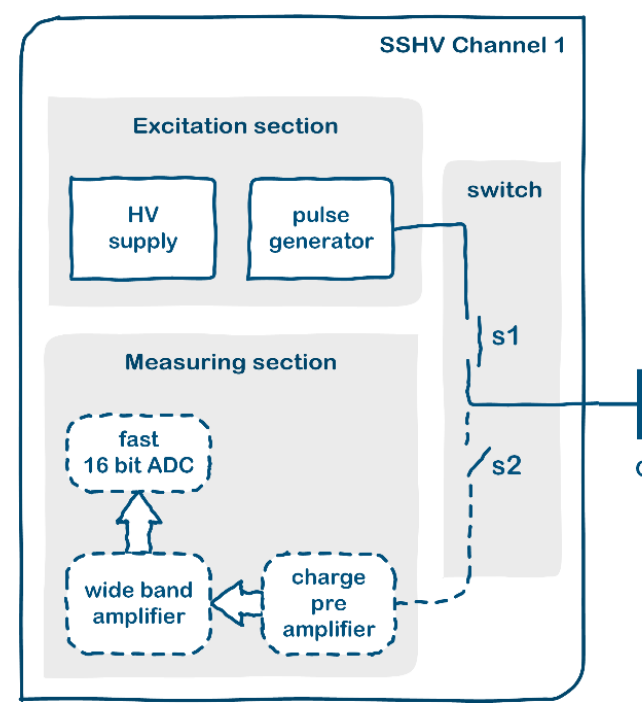

Fig. 2. Channel of the front-end board with the excitation and measuring section

EVT4 system performance is determined by a method used for the capacitance measurement. In the single-shot high voltage (SSHV) method [24], a single pulse excitation increases the speed of the measurement, whereas a high amplitude of the excitation and oversampling of the output signal preserve high signal to noise ratio. The current is integrated using a charge preamplifier while a voltage pulse is applied to the measured capacitance (Fig. 2). The height of the output pulse is proportional to the value of measured capacitance. The output signal is sampled using a fast ADC $14 \mu$ s before the pulse, during the pulse which lasts $14 \mu \mathrm{s}$ and $14 \mu \mathrm{s}$ after, giving the measurement time below $50 \mu \mathrm{s}$. Nevertheless, an additional time (about $20 \mu \mathrm{s}$ ) is needed to adjust the gain of the first and second stage amplifiers. With measurement duration of about $62 \mu$ s the theoretical speed of tomographic imaging is equal to about 500 frames per second (fps) for a multichannel tomographic system working with a sensor with 32 electrodes. Currently, each excitation is additionally delayed, so the whole measurement takes $100 \mu \mathrm{s}$ which results in $312 \mathrm{fps}$ for a 32-channel tomographic sensor.

The SSHV circuit is linear in the range from about $1 \mathrm{fF}$ to $1 \mathrm{pF}$. The signal to noise ratio (SNR) is equal from $61 \mathrm{~dB}$ for the capacitance value of about $1 \mathrm{pF}$ to $13 \mathrm{~dB}$ for $1 \mathrm{fF}$ with constant, lowest gain in the preamplifier. With the gain adjustment in the first amplifier stage, the SNR increases to $22 \mathrm{~dB}$ for measured value of $1 \mathrm{fF}$ [12]. The capacitance resolution corresponds to the root mean square (rms) of noise equal to about $0.76 \mathrm{fF} / \mathrm{bit}$ and $0.013 \mathrm{fF} / \mathrm{bit}$ for the smallest and highest gain in the preamplifier, respectively.

\subsection{D sensor design}

A typical 3D capacitance sensor has a cylindrical shape and electrodes arranged in a few rings [26, 32], however different shapes and layouts of electrodes were proposed in the literature [20]. Comparison of various three-dimensional probes were made in [25] on the basis of numerical simulation. The authors considered various topologies and the number of electrodes, from one ring with 8 electrodes up to a cubic sensor consisting of 54 electrodes surrounding the entire imaged area. To equalize the sensitivity in the whole visualized area, a three-dimensional sensor of a unique structure was proposed in [1]: a different number of electrodes in the rings (6 electrodes in the outer rings, 10 electrodes in the inner rings). The analysis of the number of electrodes of three-dimensional sensor was presented in [27]. The results obtained for various test objects shown that a 24-electrode three-dimensional probe always gives better results than a 12-electrode three-dimensional sensor. It is often proposed to move the rings relative to each other by a certain angle like in [37]. To increase the number of measurements, a multi-electrode excitation can be used [18]. In such a way the signal-to-noise ratio

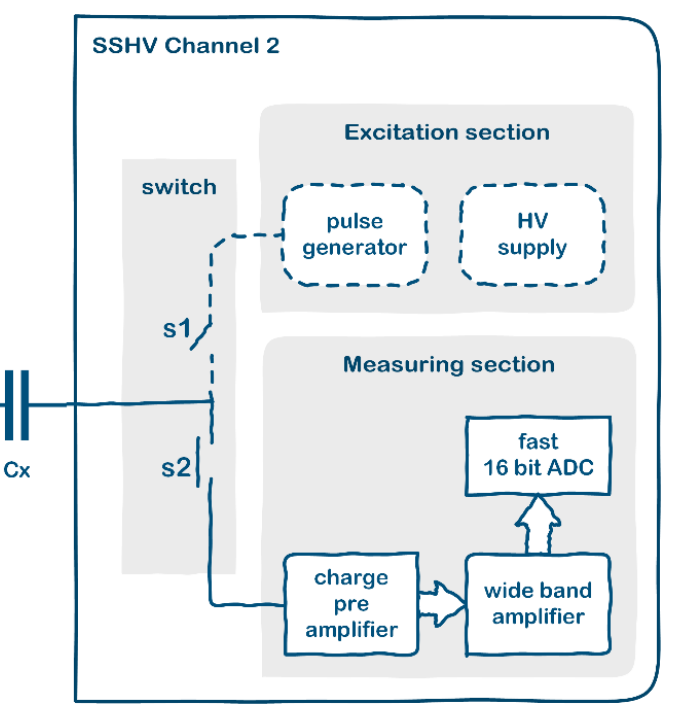

will be increased, but the spatial sampling frequency will be still small. A similar idea was proposed in [19]. The conditioning of the sensitivity matrix depends on the geometry of the electrodes. As shown in [15], the ratio of electrode lengths in $\mathrm{Z}$ axis to their angular widths equal to 0.75 is the best for a probe having 4 rings of 6 electrodes. The influence of a 3D sensor geometry on sensitivity maps has been discussed also in $[39,40]$. The more radical strategy in 3D ECT implementation is to eliminate the electrode combinations for which the measurement is not possible because of the signal value below the noise level [14].

The $3 \mathrm{D}$ sensor design is important from the measurement and image reconstruction points of view. Too long electrodes in $\mathrm{Z}$ axis make the capacitance measurement using pairs of electrodes from different outer rings impossible. Too short electrodes cause the signal-to-noise ratio to be bad for all measurements. A large measurement range of capacitance values has a reflection in a very bad condition number of the sensitivity matrix (system function) which makes the inverse problem very ill posed [14].

The 3D tomographic sensor used in the experiment was designed using the principles mentioned above. The sensor was a cylindrical tube with 32 rectangular electrodes arranged in 4 rings with 8 electrodes in each ring (Fig. 3). The inner diameter of the cylinder was $152 \mathrm{~mm}$ and the height was $195 \mathrm{~mm}$ (265 mm with the guard electrodes). The electrode geometry was adjusted heuristically to the capacitance measurement range of the EVT4 hardware. The aspect ratio of the electrode dimensions and the distance between the electrodes was selected to avoid capacitance values larger than $500 \mathrm{fF}$ for adjacent electrodes (when the sensor is fully filled with a material of maximum permittivity value) and smaller than a few $\mathrm{fF}$ for the opposite electrodes from outermost rings (when the sensor is empty). To limit the range of capacitance values, the distance between the adjacent in-ring electrodes was relatively large (half of the electrode width). To increase the mutual capacitance of the electrodes from the outermost rings, the height of the electrodes in these rings was enlarged (doubled) compared with the height of the electrodes from the central rings. The distance between rings was minimized. The smallest value of cross-ring mutual capacitance is about $2 \mathrm{fF}$ for an empty sensor. To increase sampling on the circumference [18] the electrodes in adjacent rings were shifted by a half distance between electrodes (Fig. 3a).

The electrodes were made of copper foil $(200 \mu \mathrm{m})$ mounted inside the PVC cylinder. The electrodes were insulated from the field of view of the sensor by the transparent PVC foil with the thickness equal to $0.8 \mathrm{~mm}$. PVC has dielectric breakdown voltage equal to $40 \mathrm{kV} / \mathrm{mm}$ which means that the foil is thick enough to avoid electrical breakdown when using $200 \mathrm{~V}$ in the measurement circuit. The guard electrodes were mounted outside the four rings of electrodes. The sensor was shielded using a grounded steel wire mesh surrounding the PVC tube. 
An absolute value of mutual capacitance of electrodes for the built model of a 3D sensor was calculated from measurements made using a voltage divider. A known impedance was added for the time of measurements to eliminate the influence of stray impedance on the results. The sinusoidal signal of frequency equal to $10 \mathrm{kHz}$ and known amplitude and phase was used as an excitation signal in the calibration circuit. A lock-in amplifier was used to measure real and imaginary parts of the output voltage. The uncertainty of capacitance value estimation was below $3 \%$.

The mutual capacitance of electrodes was also measured using the selected channel of the EVT4 hardware. The lowest gain in the preamplifier was used. The real value of the voltage to capacitance gain was estimated using a standard capacitor of the value equal to $100 \mathrm{fF}$. The capacitance value in farads was calculated from the ADC value using the formula:
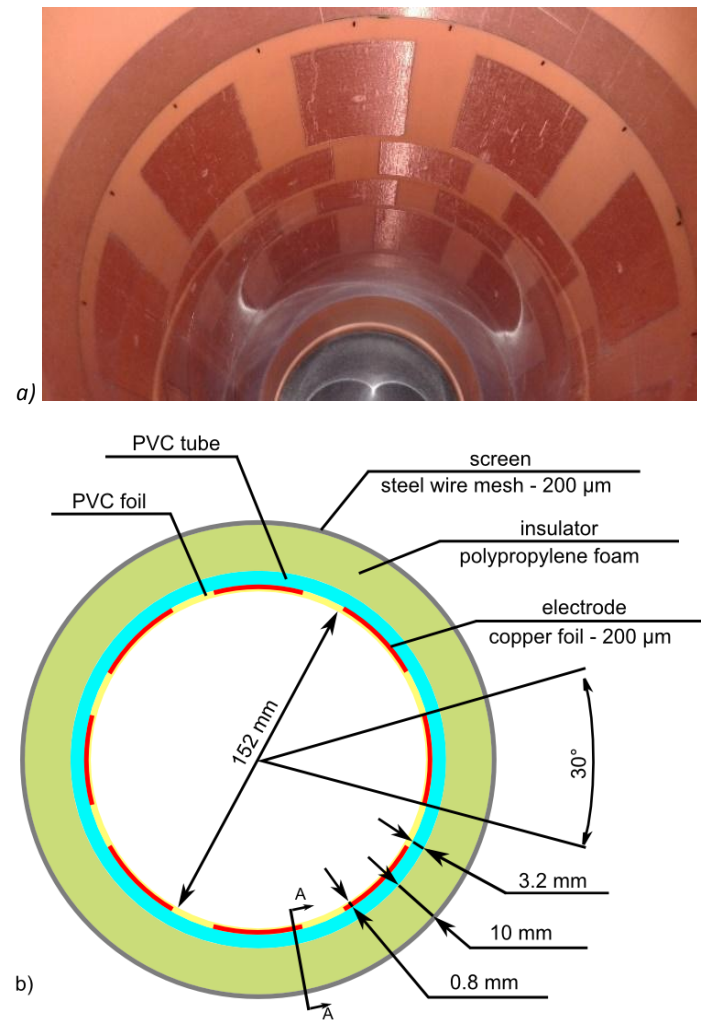

$$
C_{x}=\frac{1}{0.341}\left[\frac{p F}{V}\right] \times 4.096[V] \times \frac{\text { adc_value }}{32767}
$$

where $0.341 \mathrm{~V} / \mathrm{pF}$ is the gain of the measurement circuit, $4.096 \mathrm{~V}$ is a half of reference voltage of ADC, 32768 is a half of range of ADC. The uncertainty of single measurement of capacitance was from $1 \%$ for $300 \mathrm{fF}$ to $50 \%$ for $1 \mathrm{fF}$.

The plot of mutual capacitance values of electrode number 1 with other electrodes of the sensor is shown in Fig. 4. In the case of measurements made using the EVT4 system, the mean value from 100 measurements is taken. A characteristic U-curve for circular sensor is repeated 4 times for four rings of electrodes. The data obtained with EVT4 data acquisition system (the mean value from 100 measurements) are in accordance with the calibration measurements except the range of the smallest values.

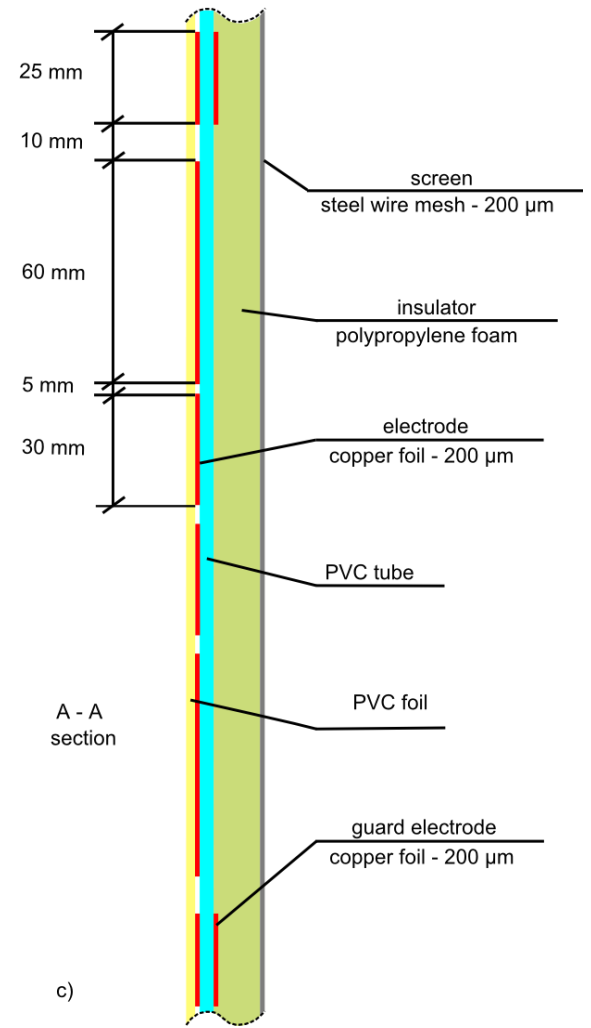

Fig. 3. 3D sensor. 32 electrodes (4 rings of 8 electrodes each). a) View of the interior of the sensor. b) Sketch of an axial cross-section. c) Sketch of a longitudinal cross-section. The size of the field of view of the sensor is not in scale with reference to other dimensions for sketch clarity

\subsection{Experimental verification of measurement sensitivity}

To evaluate the possibility of applying the EVT4 data acquisition system for three dimensional (3D) tomography, the sensitivity of capacitance measurements was verified experimentally. The sensitivity of mutual capacitance values of electrodes on a small change of permittivity value in a small volume defined as $\partial \mathrm{C} / \partial \varepsilon$ was measured by perturbing a uniform permittivity distribution by means of using a small object with low permittivity. The mutual capacitance values of electrode number 1 and the other electrodes of the sensor were measured without and with a perturbation. The cylinders of the same width and height equal to 10,20 and $30 \mathrm{~mm}$ were used. The cylinders were made of different materials: Teflon (Polytetrafluoroethylene, PTFE), Kepital (Polyoxymethylene, POM) and alumina (Aluminium oxide). The relative permittivity of these materials is given in Table 1 . Because the sensitivity map for a given pair of electrodes is not uniform, the objects were placed in the region of small sensitivity i.e. in the center of the sensor and in the region of high sensitivity, near the measuring electrode. Four positions near the opposite electrode to the electrode 1 (the excitation electrode) in each of four rings of the 3D sensor were selected as shown in Fig. 5.
Table 1. Relative electric permittivity of test objects

\begin{tabular}{|c|c|}
\hline Material & $\begin{array}{c}\text { Relative } \\
\text { permittivity }\end{array}$ \\
\hline Polytetrafluoroethylene (PTFE) (Teflon) & 2.1 \\
\hline Polyoxymethylene (POM) (Kepital F30-03) & 3.9 \\
\hline Aluminium oxide (alumina) 96\% & $9.3-11.5$ \\
\hline
\end{tabular}

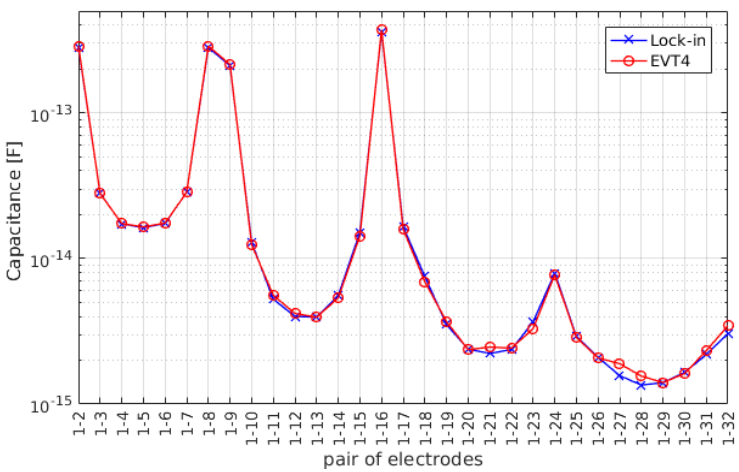

Fig. 4. Mutual capacitance of electrodes in the empty $3 D$ sensor. Capacitance value measured using the lock-in amplifier and one selected channel of the EVT4 system (mean value from 100 EVT4 measurements) 

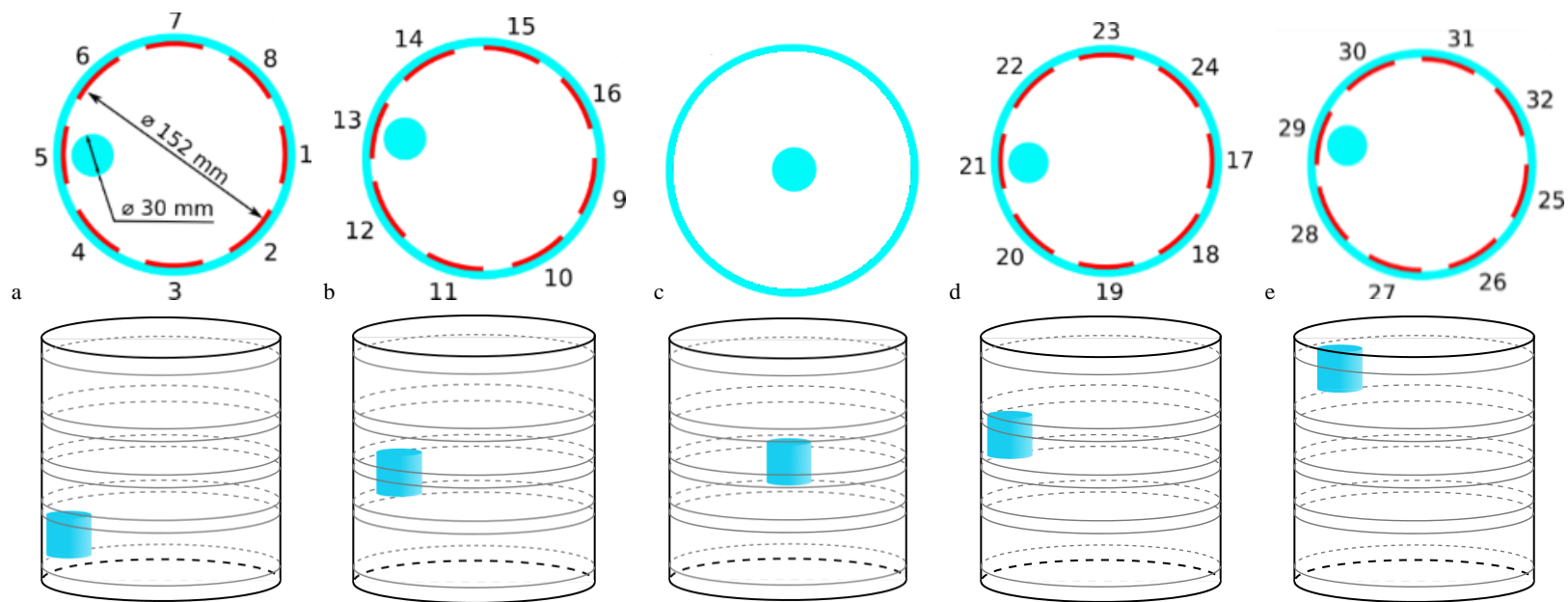

Fig. 5. Positions of the test object (cylinder of the height equal to the width) in the plane outlined by the ring of electrodes: a) top plane, b) second plane, c) third plane, d) bottom plane, e) center of sensor

All obtained measurement data were presented with normalization using minimum and maximum measurements. The empty sensor and the sensor fully filled with a material were measured to determine a range of changes in mutual capacitance of the 3D sensor electrodes. The maximum value of capacitance was registered when the sensor was filled with the granules of polyoxymethylene (POM).

\subsection{Image reconstruction}

The linear approximation of nonlinear problem existing in ECT was assumed in image reconstruction. Therefore, tomographic measurement can be described using formula:

$$
\Delta \mathrm{c}=\mathrm{S} \Delta \varepsilon
$$

where $\Delta \mathrm{c}$ is the vector of measured capacitance change, $\mathrm{S}$ is the sensitivity matrix (Jacobian matrix) and $\Delta \varepsilon$ is the vector of permittivity change in the points of a three dimensional discrete grid. The length of data vector $\Delta \mathrm{c}$ is determined by combinations of 2 electrodes from $\mathrm{K}=32$ sensor electrodes and equals $\mathrm{N}=\mathrm{K}(\mathrm{K}$ 1) $/ 2=496$. Because the spatial sampling in measurement is limited, the size of the three dimensional grid of a reconstructed spatial distribution of electrical permittivity was selected to $16 \times 16 \times 24$ voxels, each of size $9 \mathrm{~mm} \times 9 \mathrm{~mm} \times 9 \mathrm{~mm}$, in the X-, Y- and Zaxis of the cylinder, respectively. This gives $M=4968$ unknowns (a cylinder inscribed in a cuboid). The ratio of the number of measurements to the number of unknowns equals 0.1 , what is a bit less than 0.14 in case of $2 \mathrm{D}$ reconstruction of $32 \times 32$ image matrix using 120 measurements from 16 electrodes ( 804 points of a circle inscribed in a square). Thus the $3 \mathrm{D}$ inverse problem is a little more underdetermined.

The numerical model of the sensor was built and electrical field modelling was performed using ECTsim 3.0 toolbox for Matlab [11, 41]. The computed 3D sensitivity maps for capacitance measurements give the sensitivity matrix of linearized model which dimensions equal to $\mathrm{M} \times \mathrm{N}$. The condition number of the sensitivity matrix was $1.05 \mathrm{e} 7$ what indicates extreme illconditioning.

Because of channel-to-channel variability of parameters in a multichannel device, it is a good practice to normalize the measured values to the minimum-maximum in the channel. Thus, all equations of this linear system were normalized using the difference between minimal and maximal values of capacitance i.e. for the empty sensor and the sensor fully filled with the material. This procedure not only corrects channel variability but also acts as a matrix preconditioning and decreases the condition number of the sensitivity matrix to $5.82 \mathrm{e} 5$ [36].

To show that the cross-plane measurements together with the values for the pairs of most distant electrodes contain useful information, image reconstruction was performed using complete and incomplete data model. Complete data are the measurements for all electrode combinations (N_c=496). The incomplete model was built by elimination of the rows of the linear system for the measurements of pairs of electrodes for which the distance between rings is more than 2. For given electrode, the mutual capacitance of this electrode and the electrodes in the same ring and the adjacent ring are measured only. N_in=304 pairs of electrodes are included into a model with this distance. The advantage of this procedure is that the elimination of the measurements of the smallest values i.e. the most distant crossplanes electrodes from the system significantly reduces condition number to $4.77 \mathrm{e} 3$.

A unique solution of severely underdetermined problem given by (2) was found by solving minimum norm least square problem. The minimum norm solution was calculated using truncated singular value decomposition (TSVD) due to the ill-conditioning of the sensitivity matrix. The value of regularization parameter (truncation level) was calculated using the L-curve method for the incomplete model [6]. For the complete model the shape of the Lcurve did not look like an L-letter but rather as rotated W-letter with two corners. Because of this, the value of the regularization parameter was determined manually by selecting the value from the correct corner of the curve.

\subsection{Results}

The normalized capacitances (31 values for pairs with electrode no 1) measured for the test cylinder made of POM (Kepital) are shown in the Fig. 6. The data for a different diameter of the cylinder are presented in separated charts. The capacitances were normalized using maximum and minimum values obtained for the fully filled with POM and empty sensor, respectively. Five curves for five positions of the test object are plotted. The peak in each curve corresponds to the position of the test object near the receiving electrode (5th, 13th, 21th and 29th electrode) located in one of four rings of the sensor. For the position of the object in the center of the sensor, the change of the capacitance is noticeable for many electrodes, but mainly for the electrodes adjacent to the electrodes: 5th, 13th, 21th and 29th.

Other changes in the presented curves (positive and small negative) correspond to the spatial distribution of capacitance measurement sensitivity on permittivity change in a small element of space. For some electrode pairs the permittivity change (a cylindrical test object) was located in the region of positive sensitivity, but for other electrode pairs this perturbation was placed in the region of negative sensitivity. The value of the highest positive peak for each of four positions of the test object is different because of the different sensitivity distribution and different size of the electrodes. The phantom covers less of the area of the receiving electrode in case of positioning it next to the 5 th and 29th electrodes, hence the normalized capacitance change is smaller in those cases. The ratio of permittivity perturbation to the electrode pair capacitance is smaller in a case of the electrode pair 1-5 than in a case of the electrode pair 1-29 so the relative change of the capacitance is also smaller. 

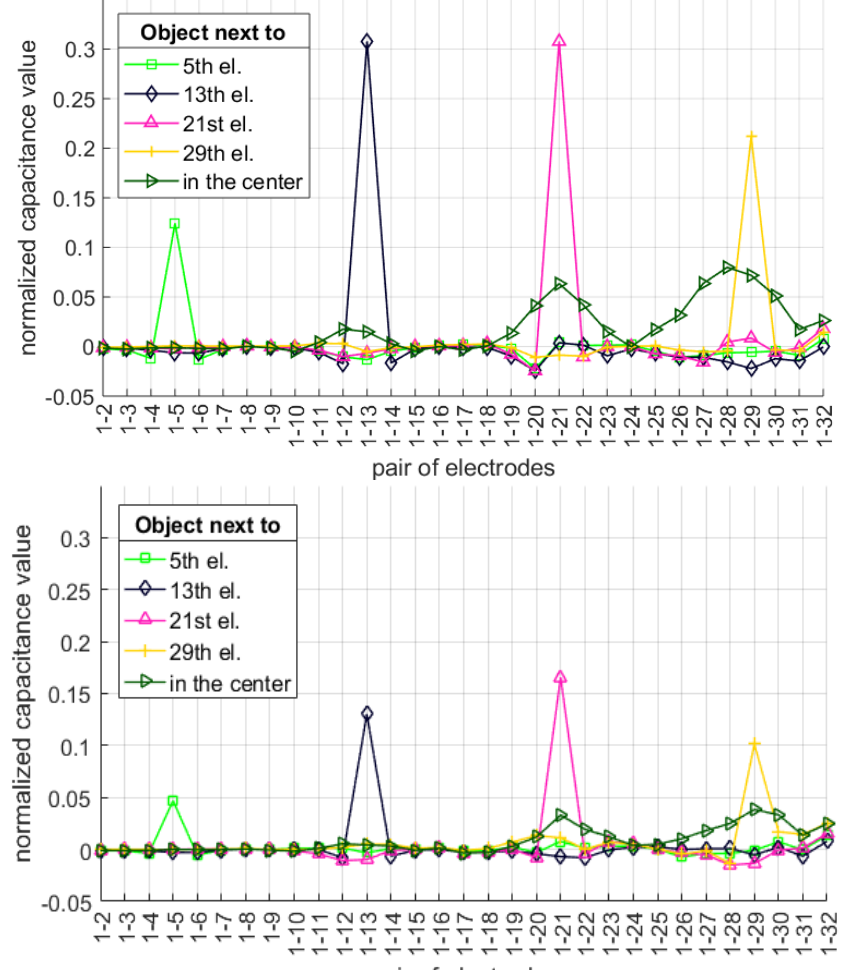

pair of electrodes

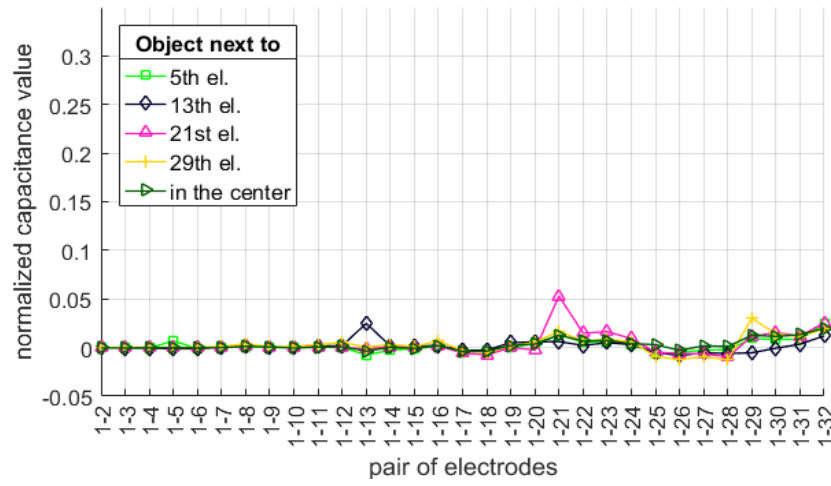

Fig. 6. Mutual capacitance of electrodes in the $3 D$ sensor for five positions of the test object (POM cylinder) of the different diameter: a) $30 \mathrm{~mm}$, b) $20 \mathrm{~mm}$; c) $10 \mathrm{~mm}$

Normalized capacitance value in a function of object size for different materials is shown in Fig. 7. The perturbation of a permittivity distribution in form of a small object causes a noticeable change of capacitance value for all tested materials. Even for the material with the lowest permittivity value it is possible to observe a change of capacitance value for all electrodes (Fig. 7c).

The three-dimensional image reconstruction of the relative permittivity distribution was performed using the measurement data registered using the EVT4 system. The cross-axial (XY plane) and longitudinal (XZ plane) slices through the $3 \mathrm{D}$ volume of the sensor were obtained for different positions of the test object. Additionally, the 3D visualization of reconstructed object was generated. The object surface was found by thresholding segmentation of relative permittivity distribution. The value of the threshold was selected heuristically. The resultant isosurface was illuminated by the Phong shading method. Fig. 8 and Fig. 9 show the reconstruction results obtained for the different size of the test cylinder: 30 and $10 \mathrm{~mm}$, accordingly. The position of the objects can be identified for all their positions however the spatial resolution is too poor to reconstruct the shape of the object. The position can be identified even for the smallest object of $10 \mathrm{~mm}$ size.
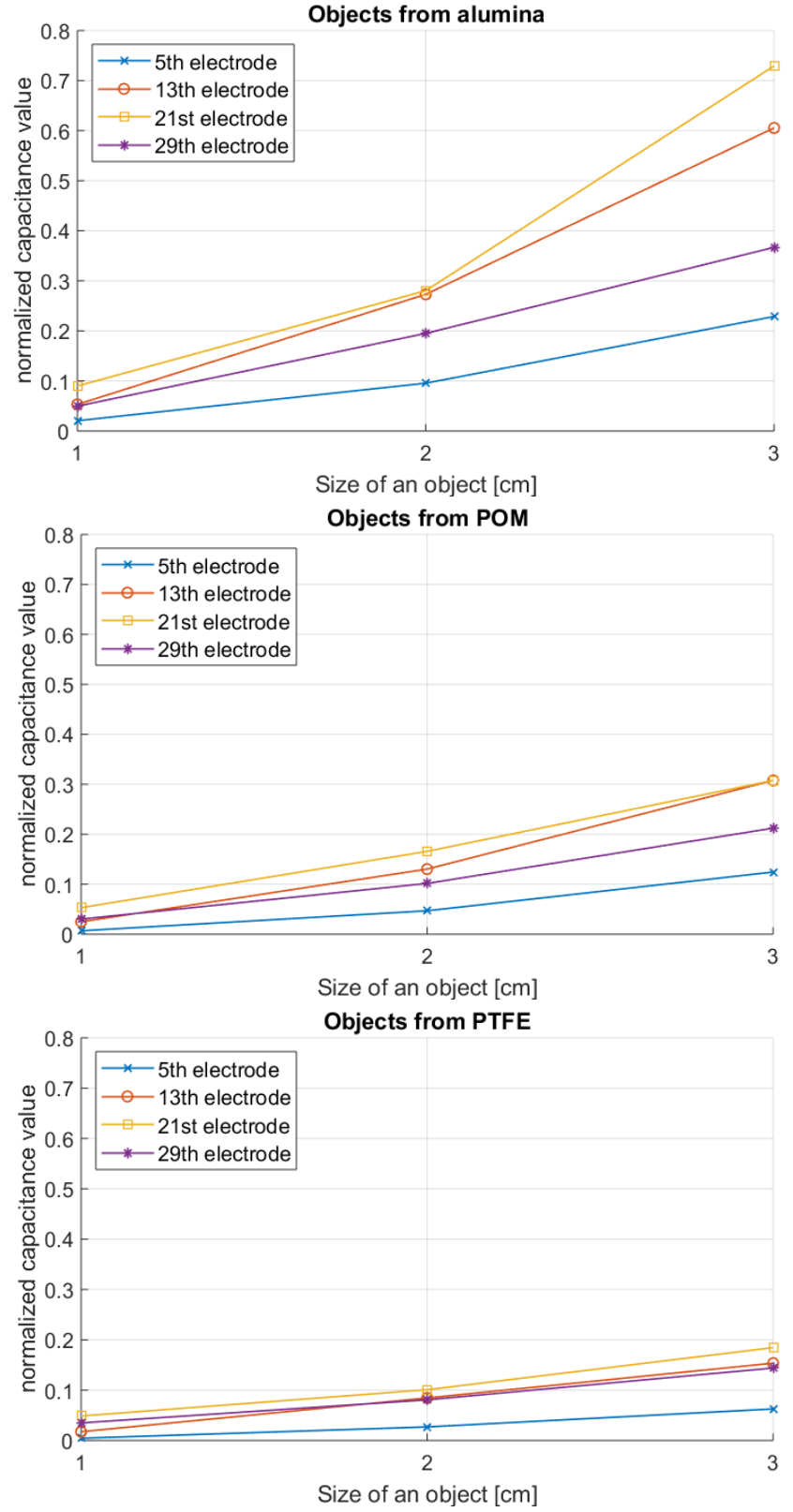

Fig. 7. Normalized mutual capacitance of electrodes in the $3 D$ sensor in function of size of the test cylinders. Three charts for objects made of: a) Teflon, b) Kepital and c) alumina). Plots for four positions of the test objects

Fig. 10 and Fig. 11 show the reconstruction results obtained for the complete set and incomplete set of measurements, 496 and 304 equations in the linear system accordingly. The slices and isosurfaces are presented for the $20 \mathrm{~mm}$ cylinder. As for the 30 and $10 \mathrm{~mm}$ objects, the shape of the object was not reconstructed well enough but the position of the object can be identified. The quality of presented images for the complete set and incomplete set is comparable, however the image reconstruction error is smaller for the images obtained using the complete model (Table 2).

Table 2. Image reconstruction error. L2 distance of the reconstructed image to the true permittivity distribution

\begin{tabular}{|c|c|c|}
\hline \multirow{2}{*}{ Material } & \multicolumn{2}{|c|}{ Number of measurements } \\
\cline { 2 - 3 } & 496 & 304 \\
\hline near the 5th electrode & 0.0268 & 0.0332 \\
\hline near the 13th electrode & 0.0446 & 0.0697 \\
\hline at center & 0.0266 & 0.0282 \\
\hline near the 21th electrode & 0.0870 & 0.0633 \\
\hline near the 29th electrode & 0.0433 & 0.0546 \\
\hline
\end{tabular}



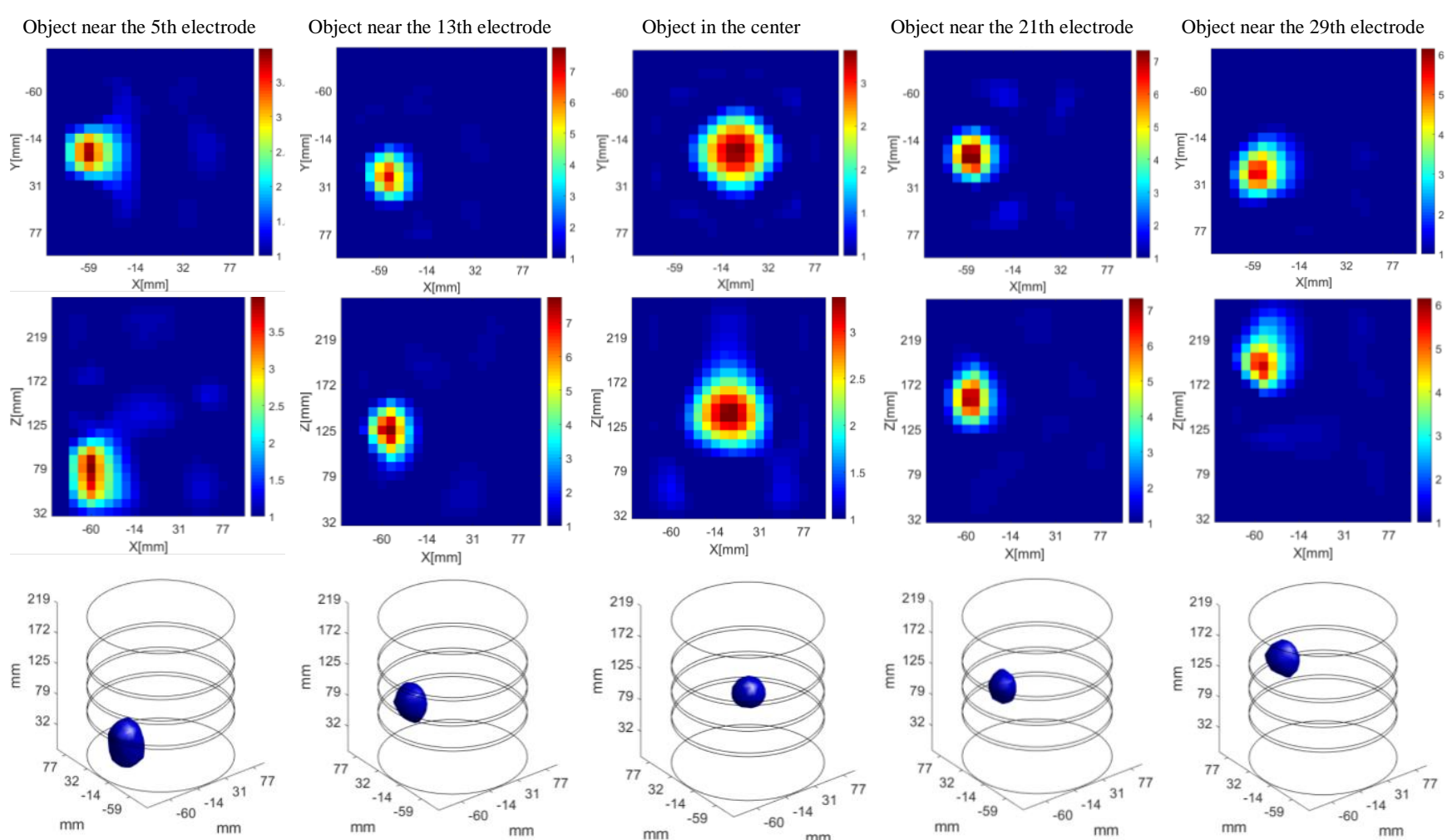

Fig. 8. 3D relative permittivity distribution obtained for a cylinder (width and height equal to $30 \mathrm{~mm}$ ) in different positions in the sensor. Upper row: XY cross-sections. Middle row: XZ cross-sections. Bottom row: Isosurface determined by threshold segmentation, shaded by the Phong method
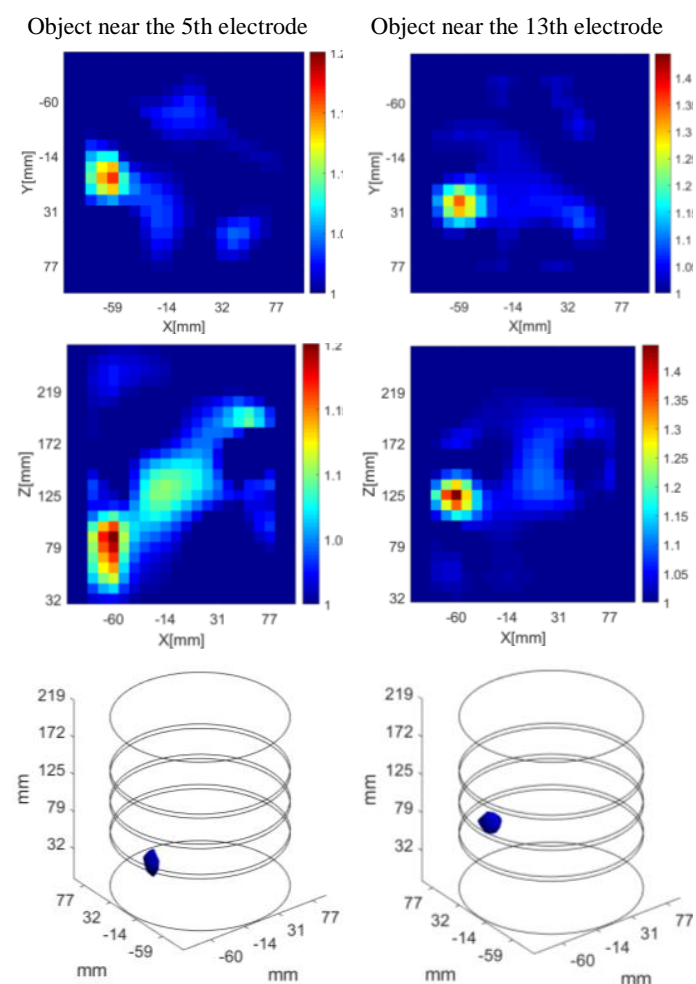

Object in the center
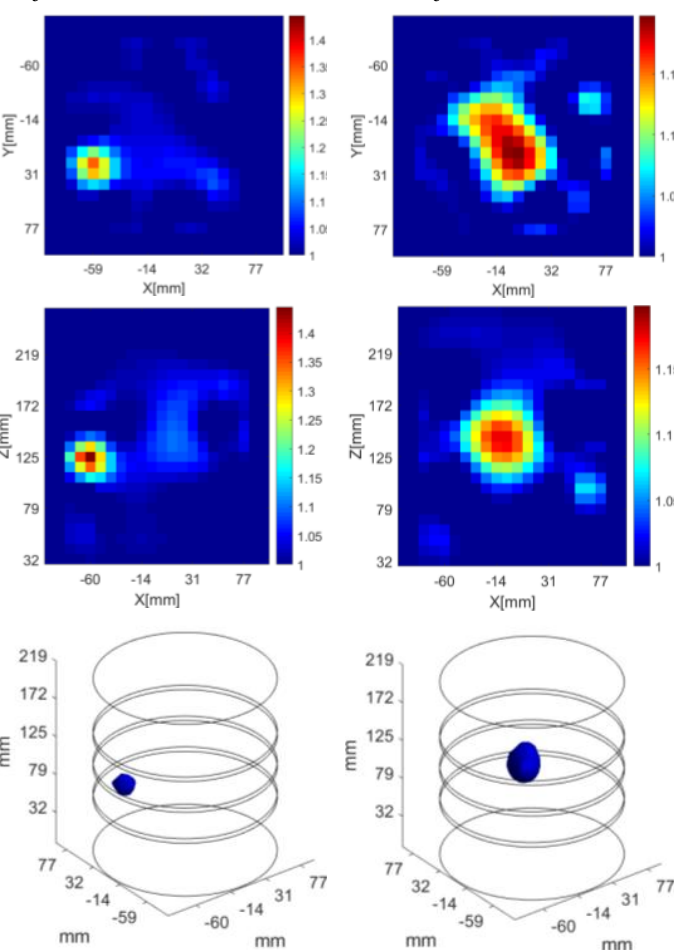
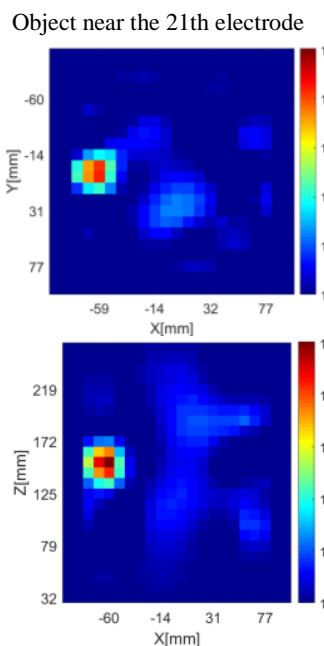

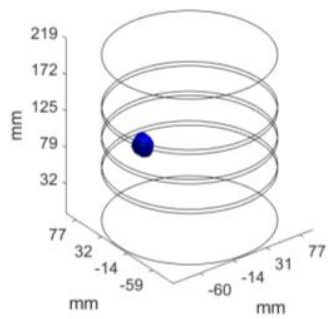

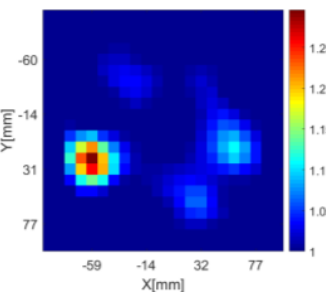
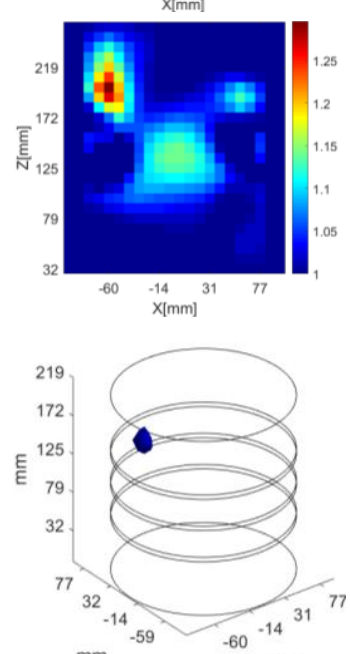

Fig. 9. $3 D$ relative permittivity distribution obtained for a cylinder (width and height equal to $10 \mathrm{~mm}$ ) in different positions in the sensor. Upper row: XY cross-sections. Middle row: XZ cross-sections. Bottom row: Isosurface determined by threshold segmentation, shaded by the Phong method 

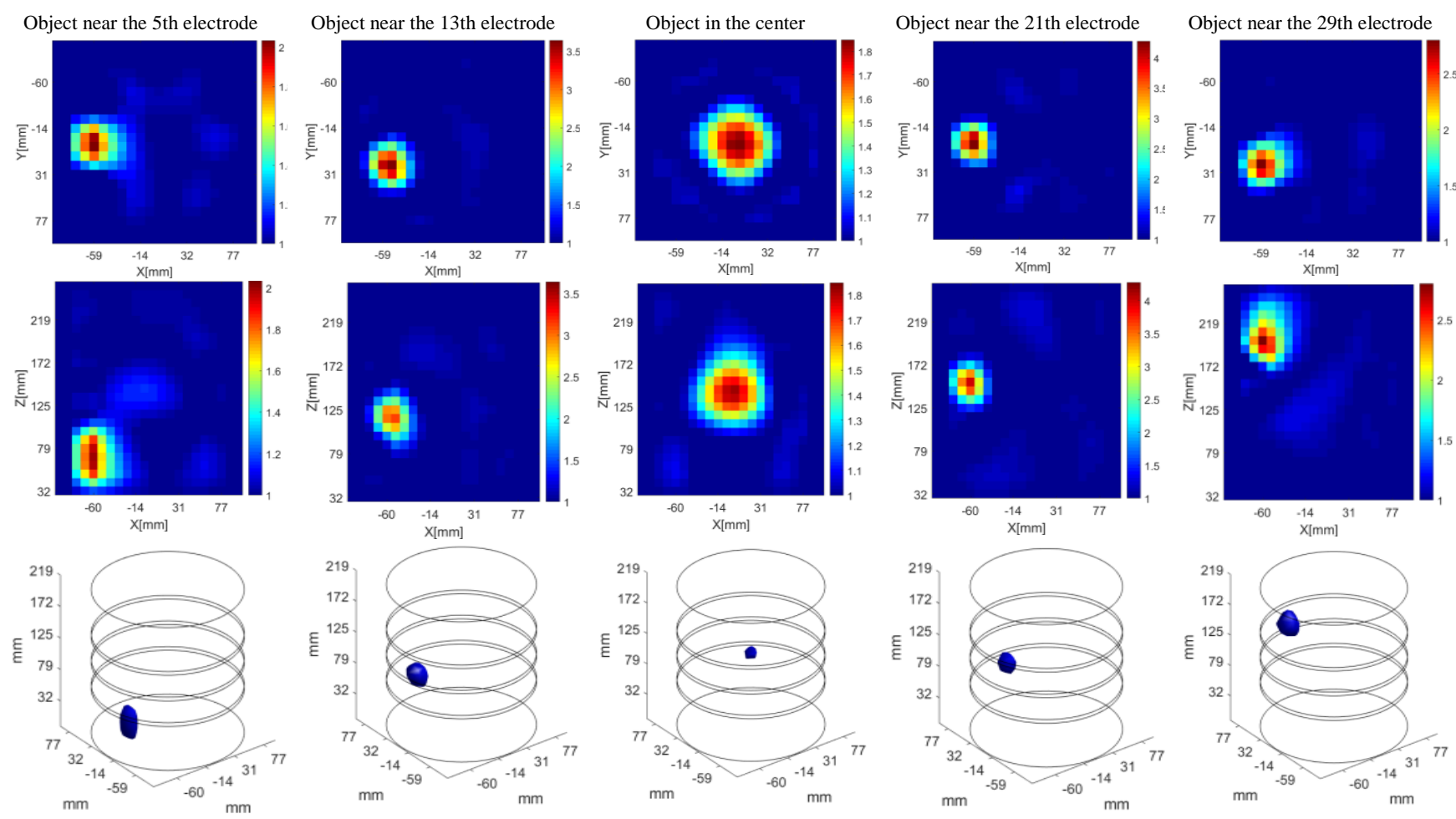

Fig. 10. 3D relative permittivity distribution obtained for a cylinder (width and height equal to $20 \mathrm{~mm}$ ) in different positions in the sensor. Inverse problem solved using the complete set of measurements (496). Upper row: XY cross-sections. Middle row: XZ cross-sections. Bottom row: Isosurface determined by threshold segmentation, shaded by the Phong method
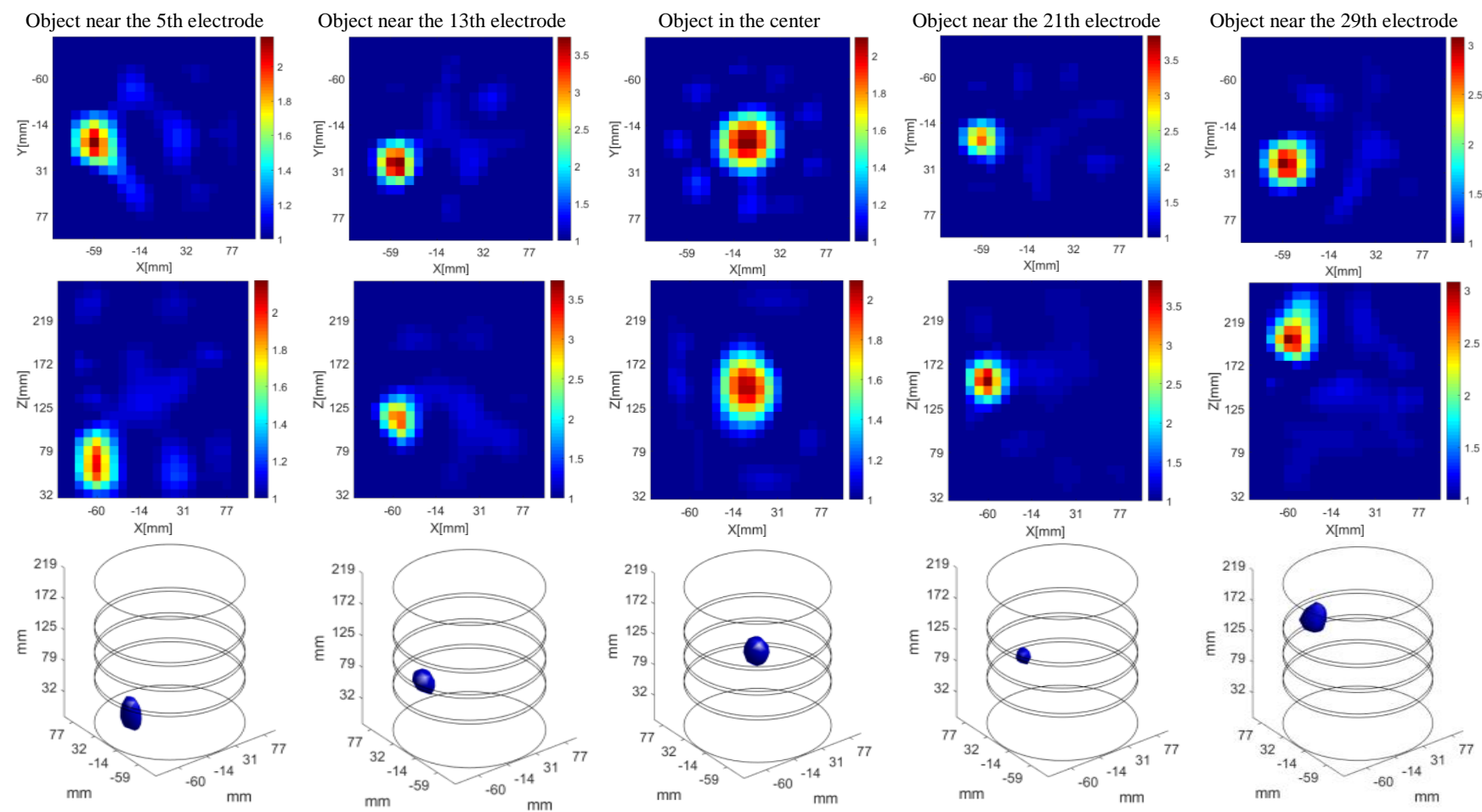

Fig. 11. 3D relative permittivity distribution obtained for a cylinder (width and height equal to $20 \mathrm{~mm}$ ) in different positions in the sensor. Inverse problem solved using selected measurements (304). Upper row: XY cross-sections. Middle row: XZ cross-sections. Bottom row: Isosurface determined by threshold segmentation, shaded by the Phong method

\section{Conclusions}

We verified a 32-channel system in a context of application for $3 \mathrm{D}$ electrical capacitance tomography. The 3D sensor was designed for experiments using principles presented in the literature. The aspect ratio of the electrode dimension and the distance between the electrodes of the 3D sensor can be selected in such a way that the difference in capacitance values between pair of adjacent electrodes and pair of the opposite electrodes will fit in the range of a measuring circuit.

The SNR of capacitance measurements in presented hardware is sufficient to measure changes in capacitance for the most distant electrodes in a suitably designed 3D 32-electrode sensor. The sensitivity of capacitance measurements was tested using objects which size is about $10 \%$ of the field of view of the sensor. The sensitivity of capacitance measurements is sufficient to detect such a permittivity change. Interestingly, the normalized sensitivity of capacitance measurement for the cross-plane electrodes is comparable to the sensitivity for in-plane electrodes for the designed 3D sensor and the selected position of the permittivity perturbation (on the edges of the field of view).

The reconstruction error for images reconstructed using the complete model is slightly, but noticeably smaller than the error obtained using the incomplete model, in which the pairs of 
electrodes between not adjacent rings are excluded. The obtained results showed that cross-plane measurements together with the measurements for the pairs of most distant electrodes are useful for accurate reconstruction of $3 \mathrm{D}$ distributions. In comparison to incomplete model, the reconstruction from complete model is more difficult from numerical point of view because of severely ill-conditioned Jacobian matrix. Applied preconditioning procedure i.e. normalization of matrix rows and adjustment of regularization parameter made the reconstruction possible.

\section{References}

[1] Banasiak R., Wajman R., Betiuk J., Soleimani M.: Feasibility study of dielectric permittivity inspection using a 3D capacitance CT method. NDT \& E International 42, 2009, 316-322.

[2] Brzeski P., Mirkowski J., Olszewski T., Plaskowski A., Smolik W. T., Szabatin R.: Multichannel capacitance tomograph for dynamic process imaging Optoelectronics Review 11(3), 2003, 175-180.

[3] Cui Z., Wang H., Chen Z., Xu Y., Yang W.: A high-performance digital system for electrical capacitance tomography. Measurement Science and Technology 22, 2011, 055503

[4] Dyakowski T., Jeanmeure L. F., Jaworski A. J.: Applications of electrical tomography for gas-solids and liquid-solids flows - a review. Powder Technology 112, 2000, 174-192.

[5] Fan Z., Gao R. X.: A new sensing method for Electrical Capacitance Tomography. IEEE Instrumentation \& Measurement Technology Conference Proceedings, 2010, 48-53.

[6] Hansen P. C.: Regularization Tools version 4.0 for Matlab 7.3. Numerical Algorithms 46, 2007, 189-194.

[7] Hu X., Katsouros M., Yang W., Huang S.: Further analysis of charge/discharge capacitance measurement circuit used with tomography sensors. Sensors and Transducers 80(6), 2007, 1246-1256.

[8] Huang S. M., Plaskowski A. B., Xie C. G., Beck M. S.: Capacitance-based tomographic flow imaging system. Electronics Letters 24(7), 1988, 418-419.

[9] Khan S., Manwaring P., Borsic A., Halter R. J.: FPGA-Based Voltage and Current Dual Drive System for High Frame Rate Electrical Impedance Tomography. IEEE Transactions on Medical Imaging 34, 2015, 888-901.

[10] Kryszyn J., Smolik W. T., Radzik B., Olszewski T., Szabatin R.: Switchles charge-discharge circuit for electrical capacitance tomography. Measurement Science and Technology 25, 2014, 115009

[11] Kryszyn J., Smolik W. T., Szabatin R.: 3D image reconstruction in electrical capacitance tomography. 7th World Congress in Industrial Process Tomography, 2013, 411-419.

[12] Kryszyn J., Wanta D., Smolik W. T.: Gain Adjustment for Signal-to-Noise Ratio Improvement in Electrical Capacitance Tomography System EVT4. IEEE Sensors Journal 17(24), 2017, 8107-8116.

[13] Kryszyn J., Wróblewski P., Stosio M., Wanta D., Olszewski T., Smolik W. T. Architecture of EVT4 data acquisition system for electrical capacitance tomography. Measurement 101, 2017, 28-39.

[14] Li Y., Holland D. J.: Fast and robust 3D electrical capacitance tomography. Measurement Science and Technology 24, 2013, 105406.

[15] Li Y., Holland D. J.: Optimizing the geometry of three-dimensional electrical capacitance tomography sensors. IEEE Sensors Journal 15(3), 2015, 1567-1574.

[16] Liao A., Zhou Q., Zhang Y.: Application of 3D electrical capacitance tomography in probing anomalous blocks in water. Journal of Applied Geophysics 117, 2015, 91-103.

[17] Lu D., Shao F., Guo Z.: A high voltage method for measuring low capacitance for tomography. Review of Scientific Instruments 80, 2009, 053704.

[18] Mao M., Ye J., Wang H., Zhang J., Yang W.: Evaluation of excitation strategy with multi-plane electrical capacitance tomography sensor. Measurement Science and Technology 27, 2016, 114008

[19] Marashdeh Q. M., Teixeira F. L., Fan L.-S.: Adaptive Electrical Capacitance Volume Tomography. IEEE Sensors Journal 14, 2014, 1253-1259.

[20] Nurge M. A.: Electrical capacitance volume tomography with high contras dielectrics using a cuboid sensor geometry. Measurement Science and Technology 18, 2007, 1511-1520.

[21] Olszewski T., Brzeski P., Mirkowski J., Plaskowski A., Smolik W. T., Szabatin R.: Capacitance tomograph - Design and preliminary results. Proc. 2rd International Symposium on Process Tomography in Poland, 2002, 159-168.

[22] Rymarczyk T.: New methods to determine moisture areas by electrica impedance tomography. International Journal of Applied Electromagnetics and Mechanics 52(1-2), 2016, 79-87

[23] Rymarczyk T., Kłosowski G., Kozłowski E.: A Non-Destructive System Based on Electrical Tomography and Machine Learning to Analyze the Moisture of Buildings. Sensors 18(7), 2018, 2285

[24] Smolik W. T., Kryszyn J., Radzik B., Stosio M., Wróblewski P., Wanta D. Dańko Ł., Olszewski T., Szabatin R.: Single-shot high-voltage circuit for electrical capacitance tomography. Measurement Science and Technology 28 , 2017, 025902.

[25] Soleimani M., Wang H., Li Y., Yang W.: A comparative study of three dimensional electrical capacitance tomography. International Journal for Information \& Systems Sciences 3(2), 2007, 292-306.

[26] Wajman R., Fiderek P., Fidos H., Jaworski T., Nowakowski J., Sankowski D., Banasiak R.: Metrological evaluation of a 3D electrical capacitance tomography measurement system for two-phase flow fraction determination. Measurement Science and Technology 24, 2013, 065302.

[27] Wang A., Marashdeh Q. M., Teixeira F. L., Fan L.-S.: Electrical Capacitance Volume Tomography: a Comparison Between 12- and 24-Channels Sensor Systems. Progress in Electromagnetics Research M 41, 2015, 73-84.
[28] Wang B., Ji H., Huang Z., Li H.: A high-speed data acquisition system for ECT based on the differential sampling method. IEEE Sensors Journal 5, 2005, 308-311.

[29] Wang F., Marashdeh Q., Fan L.-S., Warsito W.: Electrical Capacitance Volume Tomography: Design and Applications. Sensors 10, 2010, 1890-1917.

[30] Wang Mi, Ma Yixin, Holliday N., Dai Yunfeng, Williams R. A., Lucas G. A high-performance EIT system. IEEE Sensors Journal 5(2), 2005, 289-299.

[31] Warsito W., Fan L.-S.: Development of 3-Dimensional Electrical Capacitance Tomography Based on Neural Network Multi-criterion Optimization Image Reconstruction. 3rd World Congress on Industrial Process Tomography, 2003.

[32] Warsito W., Fan L.-S.: Dynamics of spiral bubble plume motion in the entrance region of bubble columns and three-phase fluidized beds using 3D ECT. Chemical Engineering Science 60, 2005, 6073-6084.

[33] Xu L., Zhou H., Cao Z.: A recursive least squares-based demodulator for electrical tomography. Review of Scientific Instruments 84, 2013, 044704.

[34] Yang W.: Design of electrical capacitance tomography sensors. Measurement Science and Technology 21, 2010, 042001.

[35] Yang W. Q.: Hardware design of electrical capacitance tomography systems. Measurement Science and Technology 7, 1996, 225-232.

[36] Yang W. Q., Peng L.: Image reconstruction algorithms for electrical capacitance tomography. Measurement Science and Technology 14, 2003, R1-R13.

[37] Ye J., Mao M., Wang H., Yang W.: An evaluation of the rotation of electrodes in multi-plane electrical capacitance tomography sensors. Measurement Science and Technology 26, 2015, 125404.

[38] York T. A., Phua T. N., Reichelt L., Pawlowski A., Kneer R.: A miniature electrical capacitance tomograph. Measurement Science and Technology 17 2006, 2119-2129.

[39] Zeeshan Z., Teixeira F., Marashdeh Q.: Sensitivity map computation in adaptive electrical capacitance volume tomography with multielectrode excitations. Electronics Letters 51, 2015, 334-336.

[40] Zhao J., Zou X., Fu W.: Sensitivity Map Analysis of Adaptive Electrical Capacitance Volume Tomography Using Nonuniform Voltage Excitation Envelopes. IEEE Sensors Journal 17, 2017, 105-112.

[41] ECTsim3D web page, http://ectsim.ire.pw.edu.pl

\section{Ph.D. Eng. Jacek Kryszyn \\ e-mail: J.Kryszyn@ire.pw.edu.pl}

Jacek Kryszyn was born in Warsaw, Poland, in 1986. $\mathrm{He}$ received his M.Sc. degree in electronics and computer engineering and the Ph.D. degree from Warsaw University of Technology, Warsaw, Poland in 2012 and 2018, respectively. $\mathrm{He}$ is an assistant professor at the Institute of Radioelectronics and Multimedia Technology, Electronics and Information Technology Faculty, Warsaw University of Technology since 2019. His field of interest covers Electrical Capacitance Tomography, especially small capacitance measurement methods

ORCID ID: 0000-0002-0042-0473

\section{M.Sc. Eng. Damian Wanta}

e-mail: D.Wanta@ire.pw.edu.pl

Damian Wanta was born in Starogard Gdański, Poland, in 1991. He received the M. Sc. degree in biomedical engineering from Warsaw University of Technology, Warsaw, Poland in 2016. He is Ph.D. student in the Nuclear and Medical Electronics Division, Institute of Radioelectronics and Multimedia Technology, Electronics and Information Technology Faculty, Warsaw University of Technology. His current research interests include Imaging of Magnetic Nanoparticles, Electrical Capacitance Tomography and Partial Reconfiguration.

ORCID ID: 0000-0002-1596-6524

\section{Prof. Waldemar T. Smolik}

e-mail:W.Smolik@ire.pw.edu.p

Waldemar T. Smolik was born in Otwock, Poland, in 1966. He received the M.Sc., Ph.D. and D.Sc. degrees in electronics engineering from Warsaw University of Technology (WUT), Warsaw, Poland in 1991, 1997 and 2014, respectively. Since 2016, he is a Professor at the Institute of Radioelectronics and Multimedia Technology, Electronics and Information Technology Faculty, WUT. He is the head of the Information Acquisition and Processing Systems Laboratory at the Division of Nuclear and Medical Electronics. His main research interests are computer engineering, computed tomography and medical imaging. He has published over 70 scientific papers.

Mr. Smolik was a recipient of the best poster award at IEEE International Workshop on Imaging Systems and Techniques in 2009.

ORCID ID: 0000-0002-1524-5049 